\title{
Excelência Humana: A Contribuição da Personalidade ${ }^{1}$
}

\author{
Seille Cristine Garcia-Santos ${ }^{2}$ \\ Pontifícia Universidade Católica do Rio Grande do Sul, Porto Alegre-RS, Brasil \\ Leandro da Silva Almeida \\ Universidade do Minho, Braga, Portugal \\ Blanca Susana Guevara Werlang \\ Pontifícia Universidade Católica do Rio Grande do Sul, Porto Alegre-RS, Brasil
}

\begin{abstract}
Resumo: Este estudo teve por objetivo analisar, sob o enfoque da Psicologia Positiva, as explicações dos pesquisadores da excelência humana sobre o que a promove e a mantém nos mais variados domínios de atuação. Constatou-se que fatores pessoais e contextuais são mencionados, destacando-se as habilidades cognitivas e a prática deliberada no desempenho superior, sendo também as variáveis de personalidade decisivas para o desenvolvimento e a manifestação da excelência. Neste estudo, como na literatura na área, destaca-se a importância da persistência, controle emocional e abertura à experiência.
\end{abstract}

Palavras-chave: psicologia positiva, personalidade, desempenho

\section{Human Excellence: The Contribution of Personality}

\begin{abstract}
This paper presents an analysis from the perspective of Positive Psychology of explanations from researchers concerning human excellence and what promotes and maintains it in the most varied domains. Personal and contextual factors are mentioned in the literature, while cognitive skills and intentional practice to achieve excellence stand out; personality variables are also critical to the development and demonstration of excellence. Based on the literature, this study suggests the importance of persistence, emotional control, and openness to experience.
\end{abstract}

Keywords: positive psychology, personality, performance

\section{Excelencia Humana: La Contribución de la Personalidad}

Resumen: El objetivo de este estudo fue analizar, desde el punto de vista de la Psicología Positiva, las explicaciones de los investigadores de la excelencia humana proponen para su desarrollo y manutencion en los mas variados campos de actividad. Se encontró que los factores personales y contextuales son mencionados, resaltándose las habilidades cognitivas y el rendimiento superior en la práctica deliberada, siendo las variables de personalidad fundamentales para el desarrollo y la demostración de la excelencia. Este estudo, basado en la literatura, destaca la importancia de la persistencia, el control emocional y apertura hacia la experiencia.

Palabras clave: psicología positiva, personalidad, desempeño

A expressão das habilidades extraordinárias e dos talentos humanos desperta o interesse tanto do cientista como do público em geral pelo enigma que representam. Um livro bem escrito, a destreza em conduzir uma bola ao gol, o brilhantismo ao tocar um instrumento musical, a desenvoltura em gerir uma pesquisa que desvenda um mistério e proporciona avanço científico chamam a atenção porque desbordam do ordinário. Muitas vezes, tais produções representam contribuições ímpares em prol do desenvolvimento e da evolução da sociedade. $\mathrm{O}$ entendimento sobre os indivíduos com esse tipo de desempenho está entre os desafios das ciências sociais e humanas.

${ }^{1}$ Artigo derivado da Tese de Doutorado da primeira autora sob orientação do segundo autor e da terceira autora, defendida no Programa de Pósgraduação em Psicologia da Pontifícia Universidade Católica do Rio Grande do Sul, em 2009. Apoio: Coordenação de Aperfeiçoamento de Pessoal de Nível Superior (CAPES).

${ }^{2}$ Endereço para correspondência:

Seille Cristine Garcia-Santos. Rua Licínio Cardoso, 350. Chácara das Pedras. CEP 91.330-470. Porto Alegre-RS, Brasil. E-mail: seille.garcia.santos@gmail.com
A Psicologia, em seu início, voltou-se fortemente para a compreensão dos males psíquicos, buscando a explicação para as dificuldades individuais, a cura para as doenças mentais e a cessação do sofrimento que elas provocam. Entretanto, a Psicologia também traz em seu cerne a compreensão do ser humano como capaz e produtivo. Os primeiros estudos nesse sentido, comparando a genialidade ao seu oposto, buscavam explicar as diferenças individuais e o que proporcionava o desempenho superior. Em meados do século passado, o movimento humanista, conduzido por Maslow e Rogers, levou a Psicologia a focar-se nos aspectos saudáveis do ser humano e no seu potencial de desenvolvimento. Em seguimento, emergiu a Psicologia Positiva investigando o otimismo, a perseverança, a virtude, a sabedoria, o bem-estar e o alto desempenho (Seligman \& Csikszentmihalyi, 2000).

Na última década, impulsionados pela Psicologia Positiva, muitos estudos vêm sendo desenvolvidos no sentido de compreender o funcionamento dos indivíduos com capacidades superiores de desempenho nos mais variados segmentos da vida humana. Esses estudos procuram descrever as características da excelência e seus fundamentos assim como 
identificar as variáveis pessoais e contextuais da excelência e em que condições esta ocorre.

A diversidade de pesquisas na área é grande. Alguns estudiosos se preocupam em entender os aspectos de construção do desempenho elevado, suas etapas ou fases (Ericsson, 2005; Renzulli, 2010); existem aqueles mais preocupados com a qualidade dos resultados produzidos, com foco na eficácia e meios para alcance dos objetivos (Zimmerman, 2002); outros enfatizam a importância da determinação, do comprometimento e das características de personalidade para o atingimento do objetivo almejado (Ardelt, 2004; Moon, 2003); há ainda os que destacam o papel do contexto daquele que atinge a excelência (Robinson \& Clinkenbeard, 1998; Sternberg, 2001). De comum, todos eles associam a excelência à performance elevada de um indivíduo numa determinada área de atuação (Trost, 2000). Por outro lado, os autores consensuam ao assumirem que a excelência requer, em alguma medida, experiência e prática em um domínio de conhecimento ou realização (Ericsson, 2005). Por último, assume-se que o desempenho excelente depende de um conjunto de fatores que abrange variáveis intrapessoais, interpessoais e contextuais que interagem de forma dinâmica e constante (Sternberg, 1999; Trost, 2000).

$\mathrm{Na}$ tentativa de organizar didaticamente os estudos sobre a excelência, Araújo, Cruz e Almeida (2007) destacaram três áreas de pesquisa consoante o enfoque: as da altas habilidades, que se dedica a associar a excelência às habilidades acima da média e ao talento; a da expertise ou perícia, que tem por objetivo avaliar o alto desempenho e rendimento superior em determinados domínios; e a da sabedoria, que associa a excelência à experiência de vida, maturidade e integridade pessoal dos sujeitos com o que atingiram elevadas performances.

Com vistas a esclarecer esses conceitos, este artigo teve por objetivo analisar, sob o enfoque da Psicologia Positiva, as explicações dos pesquisadores da excelência humana sobre o que a promove e a mantém nos mais variados domínios de atuação. Para tanto, foi realizada uma revisão da literatura, observando-se os resultados obtidos nas consultas às bases de dados: PsycArticles, SciELO, Portal de Periódicos CAPES e acervo de obras do Grupo de Investigação em Cognição, Aprendizagem e Desenvolvimento Humano da Universidade do Minho. Os descritores utilizados de forma combinada foram: human excellence; high performance; wisdom; high ability; expertise; personality; positive psychology, sendo selecionados apenas os estudos que contemplassem o funcionamento humano ótimo em contextos socialmente valorizados.

\section{Percurso Histórico dos Estudos da Excelência}

Os estudos sobre a excelência podem ser divididos em fases que mostram a trajetória de construção do conhecimento existente na área. Objetivando seguir a ordem cronológica, pode-se dizer que a primeira fase, que teve seu auge no final do século XIX, se focou na hereditariedade ou na herança genética. Nesse período, Galton (1869/1979) concedeu um status científico ao estudo da genialidade publicando o primeiro trabalho sobre o tema, Hereditary Genius, o qual enfatizava os aspectos familiares e a transmissão genética da capacidade intelectual e motivacional.

Em seguimento a esse estudo, conta Simonton (1990) que Havelock Ellis, em 1904, divulgou A Study of British Genius, afirmando existir uma conexão entre ordem de nascimento e criatividade nas pessoas consideradas geniais; James McKeen Cattell publicou A Statistical Study of Eminent Men, um estudo sobre a classificação de mil indivíduos eminentes; e Frederick Adams Woods publicou dois livros: Mental and Moral Heredity in Royalty e The Influence of Monarchs. No primeiro, o autor atrelou inteligência e virtude como traço hereditário ao avaliar famílias europeias e, no segundo, dedicado a entender a liderança, avaliou cem monarcas europeus visando mostrar que suas características de personalidade eram preditoras do bem-estar de seu país.

A segunda fase de estudos sobre excelência é marcada pela observação da personalidade e de outros aspectos psicológicos. Nessa fase, podem-se mencionar os trabalhos de Raskin (1936) com cientistas e escritores; de Thorndike (1950), relacionando inteligência e moralidade como condição da personalidade; e o de Terman (1926), que realizou uma pesquisa longitudinal com 1.500 crianças identificadas como superdotadas com base nos seus resultados em testes de inteligência (que apresentavam resultados de QI $\geq 150$ ) que apresentavam um desenvolvimento físico mais acelerado, sendo também psicologicamente estáveis e socialmente ajustadas. Esses resultados foram contrapostos por Hollingworth (1942), que verificou existirem problemas de ajustamento e dificuldades de cunho emocional em crianças de nível de inteligência muito alto. Já Cox (1926/1992) estimou os escores de personalidade de cem pessoas adultas consideradas geniais, confirmando que os traços de personalidade são complementares à inteligência na descrição do alto desempenho. Simonton (1990) ainda lembra o trabalho de Pitirim A. Sorokin, também de 1926, que associou a personalidade de monarcas e líderes políticos ao atingimento de distinção em algumas áreas, em especial na monarquia e liderança governamentais.

O próximo período de estudos sobre excelência inclui uma maior diversidade de temas com ênfase na experiência e na prática. Foi De Groot (1965/1978) quem primeiro comparou o desempenho de jogadores de xadrez especialistas e iniciantes, atribuindo a perícia aos conhecimentos prévios e a uma extensiva experiência na área, o que foi reiterado e ampliado por Simon e Chase (1973), vindo mais tarde a ser denominado por Ericsson (2005) de prática deliberada. Nesse sentido, inúmeros trabalhos surgiram compilando informações e observando o quanto e como o treinamento acelera e proporciona a excelência. Alguns desses trabalhos são os de Lubinski e Benbow (2006) e Wai, Lubinski e Benbow (2005), que buscam explicar a desenvoltura na matemática em função 
da prática; Bloom (1985), Gaspar, Ferreira e Pérez (2005), e Ruiz, Sánchez, Durán e Jiménez (2006) acrescentam um conjunto de variáveis psicológicas e afetivo-emocionais que reforçam o treinamento recebido (por exemplo, motivação, capacidade de assumir compromisso ou de estabelecer objetivos e planejar, capacidade de concentração) capazes de distinguir os atletas excelentes dos demais.

Uma fase concomitante a essa foi iniciada pelo trabalho de Maslow (1954/1970), que também inaugurou o movimento humanista na Psicologia. Esse autor focou seus estudos em pessoas de destaque (por exemplo: Lincoln, Beethoven, Eleanor Roosevelt e Einstein) e sugeriu a existência de uma sequência de necessidades a serem satisfeitas progressivamente: (1) necessidades fisiológicas; (2) necessidades de segurança; (3) de pertencimento e amor; (4) de estima; (5) de autorrealização. Maslow explicou que a autorrealização é motivadora de crescimento e, para se chegar a ela, as necessidades anteriores precisam estar supridas; considerou que as pessoas autorrealizadoras têm características de personalidade determinantes, entre elas: espontaneidade, criatividade, autonomia e independência, abertura à experiência, capacidade de relacionamento interpessoal (preferem relacionar-se com poucos, porém profundamente) e identificam-se com a humanidade. Hall, Lindzey e Campbell (2000) lembram que, para Maslow, todas as evidências (clínicas e de pesquisa) indicam que "é razoável supor que praticamente em todos os seres humanos, e certamente em quase todo bebê recém-nascido, existe um desejo ativo de saúde, um impulso para o crescimento ou para a realização das potencialidades humanas" (p. 357).

Rogers (1961/1982), considerado o pai do humanismo, também depositou um olhar científico no que há de belo e virtuoso no ser humano - latente ou manifesto - a partir da singular experiência que cada um vivenciou. Para ele, toda pessoa é capaz de utilizar seu potencial latente para fazer o que desejar e transformar-se com base numa tendência realizadora congruente com sua hereditariedade, self e contexto. Rogers ressaltou o papel da responsabilidade sobre as escolhas individuais realizadas, levando em conta o livre-arbítrio.

Depois de Rogers, nota-se uma escassez de trabalhos que, de algum modo, pudessem ampliar o entendimento alcançado sobre a excelência ou dar-lhe novos desenvolvimentos. Essa condição é rompida por Seligman e Csikszentmihalyi (2000) que, fazendo uma crítica à falta de cientificidade do humanismo, levantam uma série de questionamentos em torno da falta de conhecimento da Psicologia a respeito do funcionamento humano ótimo. Esses autores questionaram o nível de conhecimento dos psicólogos sobre a maneira como pessoas normais florescem em contextos benignos ou desafiadores, de como se sentem bem no trabalho, como ficam felizes e satisfeitas com a vida que levam.

Segundo Seligman e Csikszentmihalyi, a Psicologia operou ao longo de sua história sob três enfoques: o primeiro relaciona-se com a cura da doença mental, entendendo as psicopatologias, reparando danos e criando ferramentas para combater o sofrimento psíquico; o segundo examina como tornar a vida das pessoas mais produtivas e significativas de forma equilibrada buscando sua adequação aos contextos; e o terceiro estuda a identificação e alimentação dos talentos, atuando diretamente nas potencialidades humanas. $\mathrm{O}$ enfoque mais comum, realçam os autores, tanto nas pesquisas quanto na prática da Psicologia foi no primeiro ponto, da cura das doenças mentais. Nesse contexto, surge a Psicologia Positiva com a intenção de promover entendimentos sobre a excelência de desempenhos humanos nos mais variados domínios.

\section{Psicologia Positiva: Um Novo Enfoque da Psicologia no Presente}

A Psicologia Positiva tem sido atribuída ao trabalho de Martin Seligman, que, há uma década, efetivou inúmeras iniciativas para reunir estudos, promover debates, fazer publicações e congregar estudiosos da área no sentido de introduzir essa nova perspectiva na Psicologia (Paludo \& Koller, 2007). A Psicologia Positiva é fruto de um movimento que buscou reexaminar seus esforços científicos, redirecionando os psicólogos à apreciação do potencial humano, suas motivações e capacidades, contrariamente ao viés da Psicologia tradicional, cujo olhar focaliza apenas o que não está bem no ser humano. Não teve (ou tem) a intenção de desmerecer o trabalho já desenvolvido na Psicologia, mas busca considerar que o estudo da saúde, da realização e do bem-estar é tão meritório quanto o estudo das doenças, das disfunções e do sofrimento psíquico (Linley, Joseph, Harrington, \& Wood, 2006).

Sendo assim, o que é a Psicologia Positiva? O que pretende desenvolver? No dizer de Seligman e Csikszentmihalyi (2000, p. 5), "no nível subjetivo a Psicologia Positiva valoriza as experiências de bem-estar, contentamento e satisfação (no passado), esperança e otimismo (no futuro) e fluidez e felicidade (no presente)". Explicam os autores que, no nível individual, a Psicologia Positiva visa "à capacidade de amar, à vocação, à coragem, à habilidade interpessoal, ao talento e à sabedoria" e, no coletivo, "à responsabilidade, ao altruísmo e à proteção, civilidade, moderação, tolerância, ética e ao trabalho" (p. 5). Essa ideia é complementada por Sheldon e King (2001) quando afirmam que a Psicologia Positiva visa ao estudo científico do funcionamento ótimo do ser humano, das suas forças, potencialidades e virtudes.

Gable e Haidt (2005) reforçam o pensamento de Sheldon e King, afirmando que a Psicologia Positiva nada mais é do que "o estudo das condições e processos que contribuem para o florescimento do funcionamento ótimo das pessoas, grupos e instituições" (p. 104). Para finalizar essa tentativa de explicar a Psicologia Positiva, Sheldon e King concluem que "a Psicologia Positiva é simplesmente a Psicologia" (p. 216), retomando os objetivos iniciais dessa ciência de identificar e nutrir os talentos humanos.

Com esse novo olhar sobre o ser humano, surgiu a necessidade de se compreender como se desenvolvem os indivíduos saudáveis, aquelas pessoas que são altamente produtivas 
nos mais diversos domínios de atuação, que contribuem para o desenvolvimento da sociedade, que demonstram satisfação, bem-estar e felicidade com o como são e com o que fazem. Além disso, conforme Araújo et al. (2007), é necessário entender quais são as condições facilitadoras para se chegar a essa condição de excelência. Esses autores esclarecem que foi o advento da Psicologia Positiva que mobilizou a comunidade científica para o reconhecimento da necessidade de entender os percursos da excelência nos diversos contextos em que ela emerge.

\section{Excelência Humana e suas Áreas de Pesquisa}

O termo excelência advém do latim excellentia, que significa "qualidade de ser excelente; primazia", e, em língua portuguesa, "excelente" é a palavra utilizada para definir "aquele que é muito bom, que excede" (Ferreira, 2004, p. 852). A excelência diz do excelente como aquele que está no grau mais alto, e, em se tratando de um indivíduo, daquele que realiza algo superior, numa posição acima de tudo o que se esperava para o que foi feito, superando as expectativas, surpreendendo, criando novas possibilidades naquela área de atuação.

Embora o conceito de excelência pareça ser objetivo, quando se passa à prática surgem inúmeras ambiguidades. Variáveis genéticas, contextuais e de personalidade complexificam as linhas explicativas da excelência e a sua conceitualização. Não se verifica um satisfatório consenso sobre quais são os fatores determinantes da excelência, o que segmenta as pesquisas em diversas áreas que podem abranger o estudo de variáveis do tipo intrapessoais, interpessoais ou contextuais (Sternberg, 1999) e outras que tangenciam a dinâmica existente entre essas variáveis (Garcia-Santos, Almeida, Werlang, \& Veloso, 2010). Além disso, os estudos podem diferenciar-se consoante a sua incidência nas altas habilidades, na expertise ou perícia, ou na sabedoria (Araújo et al., 2007).

\section{Estudos sobre Altas Habilidades}

Como quase todos os conceitos da excelência, não há uma definição consensual ou uma única direção para o entendimento das altas habilidades. Sabe-se que expressa um alto nível de inteligência, um desenvolvimento mais acelerado ou precoce das funções cerebrais e que recebe interferência de fatores genéticos, psicológicos, sociais, culturais e educacionais (Gagné, 2004, 2007). Em termos legislativos brasileiros, nas diretrizes da Política Nacional de Educação Especial (Ministério da Educação, 2001), fala-se que os alunos com altas habilidades são aqueles com desempenho acima da média ou potencialidade elevada em aspectos isolados, ou combinados, em áreas como a capacidade intelectual, aptidão acadêmica, pensamento criativo, capacidade de liderança ou talento para as artes (cênicas, musicais, psicomotoras). No artigo $5^{\circ}\left(\S 3^{\circ}\right.$, p.15), as altas habilidades são explicadas como uma "grande facilidade de aprendizagem que leva o indivíduo a dominar rapidamente conceitos, procedimentos e atitudes".
O conceito que parece congregar todos esses aspectos é o de que um indivíduo com altas habilidades extrapola a média para a sua faixa etária (população em geral), possui elevados níveis de cognição, tem alta capacidade de elaboração e desempenho em uma área específica do conhecimento ou em vários domínios combinados (Alencar, 1986). Pensando dessa forma, é possível destacar pelo menos cinco modelos de trabalhos atuais que almejam contemplar o entendimento das altas habilidades.

O Modelo dos Três Anéis de Renzulli (1986, 2002, 2010) propõe que as altas habilidades sejam compreendidas como o resultado da interação de três componentes que possuem a mesma gradação de importância para o resultado: habilidade intelectual acima da média, comprometimento com a tarefa e criatividade. Nesse modelo, as altas habilidades são entendidas como um comportamento que é desenvolvido e depende de estimulação adequada, portanto é resultado de oportunidades, recursos e encorajamentos promovidos nos contextos e situações de aprendizagem.

O Modelo Diferenciado de Altas Habilidades e Talento foi proposto por Gagné (2004) e explica que as altas habilidades dependem das capacidades naturais e hereditárias, expressas espontaneamente. $\mathrm{O}$ talento é derivado da interação das habilidades naturais e do contexto de desenvolvimento do indivíduo, sujeito aos processos de aprendizagem e prática. Nesse modelo, o desenvolvimento do talento é vinculado a três tipos de fatores que podem acelerar ou atravancar o processo: os intrapessoais (personalidade, motivação), os ambientais (contexto socioeconômico, educativo, entre outros) e os fatores de sorte ou oportunidade (estar no lugar certo, no momento certo, com o preparo necessário).

O Modelo das Aptidões Inatas, Interesse e Motivação Intrínseca de Winner (2000) sugere que as aptidões inatas estão na base das altas habilidades. Nesse modelo, os indivíduos com altas habilidades possuem características cerebrais diferenciadas e tendência a interessar-se pela área ou áreas para cuja prática têm maior facilidade e propensão. Esclarece Winner que, para um indivíduo com altas habilidades chegar a ser um adulto eminente, são necessárias características de personalidade relativas à alta criatividade, à assunção de riscos e ao rompimento para com as convenções determinadas.

O Modelo da Excepcionalidade Intelectual de Castelló Tarrida (2005) considera as altas habilidades e o talento como fenômenos de natureza intelectual, como um processo de construção no qual o talento poderia ser mais simples ou mais complexo consoante as habilidades cognitivas envolvidas e os domínios de expressão, recebendo a influência de aspectos desenvolvimentais biológicos e do ambiente. $\mathrm{O}$ desenvolvimento intelectual, apesar das diferenças de ritmo para cada indivíduo, ocorre em modo contínuo, podendo ser facilitado (ou não) pela cultura que define o contexto, as oportunidades que surgem e a personalidade do indivíduo.

Por fim, o Modelo do Desenvolvimento da Expertise de Sternberg $(1998,1999)$ define altas habilidades como um processo de aquisição e cristalização de um conjunto de competências consideradas necessárias para uma elevada 
performance. Esse processo ocorre em ato contínuo, culminando na excelência em um determinado domínio de atuação. Nesse modelo conciliam-se as perspectivas das capacidades naturais e do treinamento, introduzindo os metacomponentes interacionais: competências de aprendizagem, pensamento, conhecimento e motivação (Sternberg et al., 2010).

\section{Estudos sobre Expertise ou Perícia}

Outra área da pesquisa sobre excelência aborda o tema da expertise, na qual algumas das capacidades enfatizadas nas altas habilidades deixam de ser relevantes, cedendo lugar para a experiência e prática em determinado domínio. Os estudos iniciados por De Groot (1965/1978) buscavam entender as decorrências do treinamento no desempenho e originaram a comparação entre experts e novices realizada por Simon e Chase (1973), definindo que a principal diferença entre aqueles indivíduos não se situava nos processos cognitivos básicos, mas era explicada pela prática intensa em sua área de atuação.

Compartilhando dessas ideias e questionando aquelas relativas à excelência determinada pela hereditariedade, Ericsson e Lehmann (1996) lançaram a abordagem do rendimento superior com base na prática deliberada. Esses autores conceberam a perícia como o desempenho superior em um conjunto específico de tarefas que representam um domínio. Ericsson (2005) e Ericsson, Roring e Nandagopal (2007) explicam que o rendimento superior ocorre em um processo de desenvolvimento progressivo, com base em mudanças em nível cerebral; as mudanças vão ocorrendo gradativamente, com a prática, e mesmo indivíduos com elevado potencial necessitam de treinamento para atingirem a excelência.

Para Sternberg (1998), a prática deliberada conduz os novices à perícia. Diz o autor que existe um conjunto de capacidades metacognitivas que possibilitam o desenvolvimento da perícia: o extenso conhecimento num domínio específico; a presença de unidades de conhecimento bem organizadas (em termos de armazenamento na memória), fortemente interligadas acerca de um domínio específico; a dedicação ao efetivo entendimento de determinado problema como facilitação de sua solução; desenvolvimento apurado de ranking para classificação dos problemas; estratégias para complementar o conhecimento necessário para desvendar o problema e sua solução; automatização de sequências de resolução de problemas; capacidade de resolução de problemas com a agilidade apropriada; e monitorização do implemento das soluções (Garcia-Santos et al., 2010). Conforme Sternberg, a perícia na excelência é decorrente do investimento que o indivíduo faz nas áreas onde se sente bastante competente e tem conhecimento, e da capacidade de transformar seus pontos frágeis em outros domínios (diferentes daquele no qual é perito) em aspectos irrelevantes para o seu desempenho.

\section{Estudos sobre Sabedoria}

A terceira área de estudos sobre a excelência, historicamente assentada na filosofia, é a sabedoria. Segundo
Barros-Oliveira (2005), o interesse sobre o tema atravessa a história da humanidade. Existem registros sobre a sabedoria em escritos egípcios datados de 3.000 a.C. e encontram-se inscrições sobre a sophia para os gregos, como uma dádiva dos deuses aos filósofos, uma forma de contemplação da verdade; a phrónesis como a prudência que deve revestir os homens de maior responsabilidade; e ainda, como uma grande virtude, que envolve a pessoa em busca do bem, da verdade e da beleza. Na Psicologia, o interesse por estudar a sabedoria aflorou sob o enfoque desenvolvimentalista, conectando-a à última fase do ciclo vital como o ápice, em função de ser a idade mais afeita à contemplação, à espiritualidade e à capacidade de aconselhamento. A partir de 1990, alavancada pelas pesquisas sobre as várias inteligências, Baltes e Staudinger (1993) e Sternberg (1990) retomaram os estudos sobre a sabedoria, e, mais atualmente, sob o enfoque da Psicologia Positiva e da atenção à excelência, avançam com pesquisas sobre o tema para além do trabalho tradicional da sabedoria associada à inteligência (Kunzman \& Baltes, 2003). Além disso, os psicólogos interessados em entender o que envolve a sabedoria passaram a desenvolver métodos de pesquisa para testá-la empiricamente, conferindo cientificidade ao assunto (Baltes \& Smith, 2008).

Surgiram outras definições e compreensões de sabedoria enfatizando os aspectos cognitivos, a expertise e algumas relacionando os dois fatores. Seguindo Baltes e Smith (2008), muitos pesquisadores sofreram a influência do que foi denominado Paradigma de Berlim, que resultou do trabalho de um grupo de estudiosos e apregoou que a sabedoria se constitui de um sistema de conhecimento altamente especializado sobre as formas de conduta e de compreender a vida. Assim, Horn e Masunaga (2000) consideram a sabedoria uma inteligência especial, da perícia que advém do amadurecimento da personalidade; Clayton e Birren (1980), baseados nos conhecimentos populares de sabedoria (teoria implícita), identificaram atributos das pessoas sábias: conhecimento, compreensão e experiência. Por sua vez, Sternberg (2001), ao solicitar a diversas pessoas que descrevessem indivíduos ideais em suas profissões, caracterizou a pessoa sábia como aquela que tem habilidade de raciocínio, sagacidade, perspicácia, facilidade em processar informações e em fazer julgamentos.

Além disso, Baltes e Staudinger (2000) explicam ser a sabedoria a expressão de aspectos cognitivos, porém incrementados pelos afetivo-emocionais, que, quando resultam em um comportamento correto, atingem um nível excepcional do funcionamento humano, para o qual a pessoa avaliou, sentiu e julgou uma situação-problema da melhor forma, agindo de modo equilibrado e ponderado. Complementam os autores que, com base nas teorias implícitas, se compreende a sabedoria como um conceito envolvendo maturidade, inteligência e criatividade; um nível excepcional de funcionamento humano que se relaciona à excelência; um estado de espírito e comportamento equilibrado por aspectos intelectuais, afetivos e motivacionais; enfim, a sabedoria está 
associada a um alto grau de competência intra e interpessoal, absolutamente necessária para si próprio e para os outros.

Já as teorias explícitas, baseadas nos achados empíricos e pensamento teórico de estudiosos da área, explica Barros-Oliveira (2005), dividem-se em três grupos de conceitualizações de sabedoria: (1) como característica pessoal ou de uma constelação de disposições da personalidade, (2) como produto do pensamento pós-formal e dialético e (3) como um sistema especializado sobre o significado e a conduta da vida. As três formas de abordar a sabedoria convergem para o Paradigma de Baltes (Baltes \& Kunzmann, 2004; Baltes \& Smith, 2008; Baltes \& Staudinger, 2000), que considera a sabedoria como a aplicação do conhecimento à realização intrapessoal, interpessoal e extrapessoal. Desse modo, evidencia-se a sabedoria como fruto dos aspectos cognitivos combinados com a experiência. Em oposição a essa assertiva, Ardelt $(2000,2004)$ defende a sabedoria como uma característica de personalidade ou uma combinação de qualidades pessoais reservadas às pessoas com profundo conhecimento da vida. A autora sugere que a sabedoria faz parte das pessoas e não está apenas vinculada aos conhecimentos adquiridos em função do treinamento recebido para a perícia. Ardelt (2004) avança dizendo que a avaliação da sabedoria deve ser realizada valendo-se das características pessoais relativas à gestão da vida como um todo e não da resolução de problemas hipotéticos.

\section{Personalidade e Excelência}

Desde o início dos estudos sobre a excelência, mesmo quando apenas a inteligência ou algum aspecto físico emergia como enfoque do estudo, algum traço de personalidade surgia para instigar os pesquisadores. $\mathrm{O}$ desempenho superior, em qualquer domínio de atuação em que apareça, associa-se a traços de personalidade predisponentes à facilitação da emergência das capacidades e potencialidades requeridas para aquele desempenho. Holland (1997) elaborou uma teoria cujo trabalho, apesar de não ter o propósito de fazer descobertas relacionadas à excelência, possibilitou enriquecer o entendimento de como a personalidade está associada e influencia as escolhas que um indivíduo faz quando se dedica a uma realização ímpar. Esclarece o autor que os interesses demonstrados por uma pessoa, suas preferências durante a vida, sua escolha vocacional ou a carreira profissional que desenvolve são a expressão da sua personalidade, de forma a acomodá-la a um ambiente ocupacional congruente.

Com base no Modelo Hexagonal RIASEC, Holland explica que cada vértice do hexágono consolida um dos seis tipos de personalidade. $\mathrm{O}$ tipo realístico $(\mathrm{R})$ interessa-se mais por trabalhar com máquinas, ferramentas e manipulação de objetos; prefere ambiente aberto, aprecia a natureza, interessa-se por solucionar problemas práticos. O tipo investigativo (I) é voltado para a exploração de ideias, análise de dados, teorias explicativas; interessa-se por resolver problemas matemáticos, interpretar fórmulas; é mais introvertido, menos sociável, prefere ambiente fechado e independência. O tipo artístico (A) aprecia criar coisas novas, é imaginativo e inovador; prefere atividades individuais, não aprecia rotinas e regras, é voltado para a emoção. O tipo social (S) interessa-se por ajudar pessoas e ensiná-las, trabalhar em grupos, planejar atividades; prefere lidar com pessoas. O tipo empreendedor (E) interessa-se por atividades e ambientes onde possa persuadir, tomar decisões, negociar, iniciar e promover projetos, convencer outros; é persistente e entusiasmado. $\mathrm{O}$ tipo convencional (C) é voltado para o trabalho com números e programas de computador, aprecia ambiente estruturado onde possa responsabilizar-se por detalhes; é organizado, eficiente e consciencioso.

Conforme o pensamento de Holland (1997), a personalidade se acomoda ao ambiente ocupacional que lhe é mais confortável. Todos os tipos do modelo se interligam e os interesses de uma pessoa podem pertencer a mais de um dos tipos entre os seis do hexágono. Apesar disso, haverá um domínio mais marcante no indivíduo, aquele em que demonstrará e concretizará seus interesses e suas preferências, caracterizando seu ponto forte, no qual terá maior desenvoltura e, portanto, maior desempenho e satisfação pessoal, especialmente se o indivíduo receber estimulação adequada ou desafiadora.

A teoria de Holland associa a personalidade ao contexto/ambiente, o que também já foi explorado por alguns autores dispostos a explicar a excelência. Assim, Moon (2003), ao definir talento pessoal como uma excepcional habilidade de selecionar e atingir objetivos de vida difíceis que se relacionem com interesses pessoais, valores e o contexto em que está inserido o indivíduo, explica que o talento está condicionado a fatores intrapessoais e interpessoais e à inteligência social. Staudinger, Lopez e Baltes (1997) apontam a relevância para a sabedoria de características de personalidade, como a maturidade, a ausência de instabilidade emocional, a abertura de espírito e a sociabilidade, lembrando os trabalhos de Clayton e Birren (1980) e Holliday e Chandler (1986), uma vez que esclarecem ser a abertura à experiência e a abertura de espírito os mais fortes preditores de sabedoria relacionados à personalidade.

Parece que a preocupação de Cox (1926/1992) em explicar que alguns traços da personalidade são complementares à inteligência e a tudo mais que circunda a excelência obteve seguidores. Tanto nos estudos das altas habilidades como nos da expertise e nos da sabedoria, houve interesse em saber em que grau alguns aspectos da personalidade falavam mais alto na determinação da excelência. Expõe Simonton (1990) que estudos conduzidos por Woods constataram haver influência da personalidade dos monarcas europeus no bem-estar do povo de sua nação; Thorndike (1950) relacionou moralidade e personalidade, o que foi estudado mais tarde por Orwoll e Perlmutter (1990) associando sabedoria com maturidade de caráter e integridade. Nas pesquisas sobre a expertise, o enfoque na personalidade aparece nos trabalhos de Gaspar et al. (2005), de Ruiz et al. (2006) e de Poczwardowski e Conroy (2009), tomando, por exemplo, a 
interferência dos aspectos afetivo-emocionais no desempenho dos atletas excelentes. Também Maslow (1954/1970), ao estudar pessoas eminentes, focou-se em desvendar características de personalidade das pessoas autorrealizadoras; e Rogers (1961/1982) destacou a congruência necessária entre personalidade e a tendência realizadora do self.

Silverman (1993) explicou que pessoas com altas habilidades possuem características específicas de personalidade que constituem um jeito de ser peculiar. Entre elas estão a facilidade em perceber, paixão por aprender, imaginação vívida, intensidade de dedicação ao que fazem, perseverança, busca pela perfeição, sensibilidade e empatia; além de possuírem autoconsciência, capacidade de reflexão e tendência à introversão, possuem senso agudo de justiça, questionam regras e a autoridade e têm preocupação moral precoce. Na mesma linha, Winner (2000) afirma existirem características de personalidade específicas para que uma criança chegue a ser um adulto eminente, quais sejam, criatividade, abertura à experiência e rompimento com as convenções. Essas características de personalidade emergem como necessárias ao desenvolvimento dos talentos (Castelló Tarrida, 2005; Gagné, 2004).

\section{Considerações Finais}

Os estudos sobre a excelência, enquadrados no âmbito da Psicologia Positiva, são atravessados por considerações sobre as variáveis determinantes das prestações superiores de alguns indivíduos nas diferentes áreas do desempenho. Entre os autores referidos parece não restar dúvida de que não importa a herança genética nem o contexto ou os favorecimentos da sorte, tampouco os conhecimentos e a inteligência. Se a pessoa não tiver alguns traços de personalidade facilitadores da perseverança, das relações sociais assertivas, das condições afetivo-emocionais apropriadas, da criatividade, da firmeza de propósito e da gestão emocional, entre várias outras características de personalidade, nada acontecerá no sentido do rendimento superior.

Atualmente, em termos da avaliação e atenção às altas habilidades, parece não ser à toa que, em algumas escolas situadas nos países nórdicos da Europa, no Reino Unido e nos Estados Unidos da América, tenha-se o cuidado de avaliar os interesses e a personalidade de crianças desde tenra idade. Com base nas preferências encontradas, passam a ser estimuladas e desde cedo acompanhadas no sentido de desenvolver-se em domínios para os quais tenham maior facilidade, aprofundando-se e destinando seus esforços físicos e intelectuais ao que é congruente com sua personalidade, seguindo o pensamento de Holland (1997).

Quanto à expertise, inúmeros são os esforços, especialmente na área dos esportes, onde a superação tem sido a palavra-chave, para confirmar que equilíbrio (intra, inter e extrapessoal), definição de metas, concentração, treinamento intensivo e perseverança conduzem ao pódio. Para não ficar atrás, inicia-se o movimento no setor das organizações, em treinar e qualificar pelo aprendizado seus melhores funcionários (entendidos como aqueles que têm alto desempenho combinado com inteligência, conhecimentos, comprometimento e características de personalidade favoráveis), para que façam a diferença em um mundo dos negócios acirradamente competitivo como é o da atualidade. E a exploração da sabedoria vem produzindo estudos sofisticados que intentam apreender a essência da excelência, associando grande número de características positivas num único indivíduo aos resultados práticos de compreensão excepcional da vida, maturidade, integridade vívida, e outras capacidades que possam dar indicativos de ser aquela pessoa sábia.

A Psicologia levou cem anos para chegar onde está, não há como saber onde estará daqui a cem anos, mas é bem possível que os conhecimentos gerados pela Psicologia Positiva e os estudos da excelência estejam incorporados à Psicologia de tal modo que façam parte dela. Espera-se que apreciar as nuanças de felicidade e bem-estar nas pessoas, suas causas e seus efeitos, venham a ser inerentes a essa ciência, assim como a construção de estratégias psicológicas centradas naquilo que faz valer a pena viver, conferindo sentido e resultando em um funcionamento humano ótimo.

O desenvolvimento e a estimulação do potencial humano irrompem como uma das maiores preocupações do mundo moderno, por parecer ser essa uma das mais efetivas possibilidades de assegurar a sobrevivência do ser humano sobre a Terra. São os excelentes que, por meio de suas realizações ímpares, alteram os padrões prévios dos modelos estabelecidos, arriscam-se no novo e produzem soluções inesperadas para aquilo que se tinha até o momento. Pensando assim, a promoção da excelência, em todos os domínios socialmente valorizados, é de extrema necessidade e urgência, simplesmente pelo momento em que a humanidade se encontra.

\section{Referências}

Alencar, E. M. L. S. (1986). Psicologia e educação do superdotado. São Paulo: EPU.

Araújo, L. S., Cruz, J. F. A., \& Almeida, L. S. (2007). Excelência humana: Teorias explicativas e papel determinante do professor. Psicologia, Educação $e$ Cultura, 11(2), 197-221.

Ardelt, M. (2000). Intellectual versus wisdom-related knowledge: The case for a different kind of learning in the later years of life. Educational Gerontology, 26(8), 771-789. doi:10.1080/036012700300001421

Ardelt, M. (2004). Where can wisdom be found? A reply to the commentaries by Baltes and Kunzmann, Sternberg, and Achenbaum. Human Development, 47(5), 304-307. doi:10.1159/000079158

Baltes, P. B., \& Kunzmann, U. (2004). The two faces of wisdom: Wisdom as a general theory of knowledge and judgment about excellence in mind and virtue vs. wisdom as everyday realization in people and products. Human Development, 47(5), 290-299. doi:10.1159/000079156 
Baltes, P. B., \& Smith, J. (2008). The fascination of wisdom: Its nature, ontogeny, and function. Perspectives on Psychological Science, 3(1), 56-64. doi:10.1111/j.17456916.2008.00062.x

Baltes, P. B., \& Staudinger, U. M. (1993). The search for a psychology of wisdom. Current Directions in Psychological Science, 2(3), 75-80. doi: 10.1111/14678721.ep10770914

Baltes, P. B., \& Staudinger, U. M. (2000). Wisdom: A metaheuristic (pragmatic) to orchestrate mind and virtue toward excellence. American Psychologist, 55(1), 122136. doi:10.1037/0003-066X.55.1.122

Barros-Oliveira, J. H. (2005). Sabedoria: Definição, dimensionalidade e educabilidade. Revista Portuguesa de Pedagogia, 39(2), 151-173.

Bloom, B. S. (Ed.). (1985). Developing talent in young people. New York: Ballantine.

Castelló Tarrida, A. (2005). Aproximación a la evaluación de la superdotación y los talentos. In M. Sánchez-Cano \& J. B. Picas (Coords.), La evaluación psicopedagógica (pp. 383-415). Barcelona, España: Graó.

Clayton, V. P., \& Birren, J. E. (1980). The development of wisdom across the life span: A re-examination of an ancient topic. In P. Baltes \& O. Brim, Jr. (Eds.), Lifespan development and behavior (pp. 104-137). New York: Academic Press.

Cox, C. M. (1992). The early mental traits of 300 geniuses. In R. S. Albert (Ed.), Genius \& eminence (2nd ed., pp. 53-58). Oxford, England: Pergamon. (Original publicado em 1926)

De Groot, A. D. (1978). Thought and choice in chess (2nd ed.). The Hague: Mouton. (Original publicado em 1965)

Ericsson, K. A. (2005). Recent advances in expertise research: A commentary on the contributions to the special issue. Applied Cognitive Psychology, 19(2), 233241. doi:10.1002/acp.1111

Ericsson, K. A., \& Lehmann, A. C. (1996). Expert and exceptional performance: Evidence ofmaximal adaptation to task constraints. Annual Review of Psychology, 47, 273-305. doi:10.1146/annurev.psych.47.1.273

Ericsson, K. A., Roring, R. W., \& Nandagopal, K. (2007). Giftedness and evidence for reproducibly superior performance: An account based on the expert performance framework. High Ability Studies, 18(1), 3-56. doi:10.1080/13598130701350593

Ferreira, A. B. H. (2004). Novo dicionário Aurélio da língua portuguesa (3a ed.). Curitiba: Positivo.

Gable, S. L., \& Haidt, J. (2005). What (and why) is positive psychology? Review of General Psychology, 9(2), 103110. doi:10.1037/1089-2680.9.2.103

Gagné, F. (2004). Transforming gifts into talents: the DMGT as a developmental theory. High Ability Studies, 15(2), 119-147. doi:10.1080/1359813042000314682

Gagné, F. (2007). Ten commandments for academic talent development. Gifted Child Quarterly, 51(2), 93-118. doi:10.1177/0016986206296660
Galton, F. (1979). Hereditary genius: An inquiry into its laws and consequences. London, England: Julian Friedman. (Original publicado em 1869)

Garcia-Santos, S. C., Almeida, L. S., Werlang, B. S. G., \& Veloso, A. L. M. (2010). Processamento da informação em gestores de alto desempenho. Motricidade, 6(1), 85-102.

Gaspar, P., Ferreira, J. P., \& Pérez, L. M. R. (2005). Tomadas de decisão no desporto: O seu ensino em jovens atletas. Revista Mackenzie de Educação Física e Esporte, 4(4), 95-111.

Hall, C. S., Lindzey, G., \& Campbell, J. B. (2000). Teorias da personalidade (M. A. V. Veronese, Trad., 4a ed.). Porto Alegre: Artmed.

Holland, J. L. (1997). Making vocational choices: A theory of vocational personalities and work environments (3rd ed.). Odessa, FL: Psychological Assessment Resources.

Holliday, S. G., \& Chandler, M. J. (1986). Wisdom: Explorations in adult competence. Basel, Switzerland: Karger.

Hollingworth, L. S. (1942). Children above 180 IQ, StanfordBinet: Origin and development. New York: World Book.

Horn, J. L., \& Masunaga, H. (2000). On the emergence of wisdom: Expertise development. In W. S. Brown (Ed.), Understanding wisdom: Sources, science, and society (pp. 245-276). West Conshohocken, PA: Templeton.

Linley, P. A., Joseph, S., Harrington, S., \& Wood, A. M. (2006). Positive psychology: Past, present, and (possible) future. The Journal of Positive Psychology, 1(1), 3-16. doi:10.1080/17439760500372796

Lubinski, D., \& Benbow, C. P. (2006). Study of mathematically precocious youth after 35 years: Uncovering antecedents for the development of math-science expertise. Perspectives on Psychological Science, 1(4), 316-345. doi:10.1111/j.1745-6916.2006.00019.x

Maslow, A. H. (1970). Motivation and personality (2nd ed.). New York: Harper \& Row. (Original publicado em 1954)

Ministério da Educação. Secretaria de Educação Especial. (2001). Diretrizes nacionais para a educação especial na educação básica. Recuperado em 29 de janeiro de 2010, de http://portal.mec.gov.br/seesp/arquivos/pdf/diretrizes.pdf

Moon, S. M. (2003). Personal talent. High Ability Studies, 14(1), 5-21. doi:10.1080/13598130304095

Orwoll, L., \& Perlmutter, M. (1990). The study of wise persons: Integrating a personality perspective. In $\mathrm{R}$. J. Sternberg (Ed.), Wisdom: Its nature, origins, and development (pp. 160-177). New York: Cambridge University Press.

Paludo, S. S., \& Koller, S. H. (2007). Psicologia positiva: uma nova abordagem para antigas questões. Paidéia (Ribeirão Preto), 17(36), 9-20. doi:10.1590/S0103863X2007000100002

Poczwardowski, A., \& Conroy, D. E. (2009). Coping responses to failure and success among elite athletes and performing artists. Journal of Applied Sport Psychology, 14(4), 313-329. doi:10.1080/10413200290103581 
Raskin, E. A. (1936). Comparison of scientific and literary ability: A biographical study of eminent scientists and men of letters of the nineteenth century. Journal of Abnormal and Social Psychology, 31(1), 20-35. doi:10.1037/h0060483

Renzulli, J. S. (1986). The three-ring conception of giftedness: A developmental model for creative productivity. In R. J. Sternberg \& J. E. Davidson (Eds.), Conceptions of giftedness (pp. 53-92). New York: Cambridge University Press.

Renzulli, J. S. (2002). Emerging conceptions of giftedness: Building a bridge to the new century. Exceptionality, 10(2), 67-75. doi:10.1207/S15327035EX1002_2

Renzulli, J. S. (2010). El rol del profesor en el desarrollo del talento. Revista Electrónica Interuniversitária de Formación del Profesorado, 13(1), 33-40.

Robinson, A., \& Clinkenbeard, P. R. (1998). Giftedness: An exceptionality examined. Annual Review Psychology, 49, 117-139. doi:10.1146/annurev.psych.49.1.117

Rogers, C. R. (1982). Tornar-se pessoa (M. J. C. Ferreira, Trad.). São Paulo: Martins Fontes. (Original publicado em 1961)

Ruiz, L. M., Sánchez, M., Durán, J., \& Jiménez, C. (2006). Los expertos en el deporte: Su estudio y análisis desde una perspectiva psicológica. Anales de Psicología, 22(1), 132-142.

Seligman, M. E. P., \& Csikszentmihalyi, M. (2000). Positive psychology: An introduction. American Psychologist, 55(1), 5-14. doi:10.1037/0003-066X.55.1.5

Sheldon, K. M., \& King, L. (2001). Why positive psychology is necessary. American Psychologist, 56(3), 216-217. doi:10.1037/0003-066X.56.3.216

Silverman, L. K. (1993). Counseling needs and programs for the gifted. In K. A. Heller, F. J. Mönks, \& A. H. Passow (Eds.), International handbook of research and development of giftedness and talent (pp. 631-647). Elmsford, NY: Pergamon.

Simon, H. A., \& Chase, W. G. (1973). Skill in chess. American Scientist, 61(4), 394-403.

Simonton, D. K. (1990). Psychology, science, and history: Introduction to historiometry. New Haven, CT: Yale University Press.

Staudinger, U. M., Lopez, D. F., \& Baltes P. B. (1997). The psychometric location of wisdom-related performance: Intelligence, personality, and more? Personality and Social Psychology Bulletin, 23(11), 1200-1214. doi:10.1177/01461672972311007

Sternberg, R. J. (Ed.). (1990). Wisdom: Its nature, origins, and development. New York: Cambridge University Press.

Sternberg, R. J. (1998). Metacognition, abilities, and developing expertise: What makes an expert student? Instructional Science, 26(1-2), 127-140. doi:10.1023/A:1003096215103

Sternberg, R. J. (1999). Intelligence as developing expertise. Contemporary Educational Psychology, 24(4), 359-375. doi: 10.1006/ceps.1998.0998
Sternberg, R. J. (2001). Giftedness as developing expertise: A theory of the interface between high abilities and achieved excellence. High Ability Studies, 12(2), 159179. doi:10.1080/13598130120084311

Sternberg, R. J., Grigorenko, E., Ferrando, M., Hernández, D., Ferrándiz, C., \& Bermejo, R. (2010). Enseñanza de la inteligência exitosa para alumnos superdotados y talentos. Revista Electrónica Interuniversitária de Formación del Profesorado, 13(1), 111-118.

Terman, L. M. (1926). Mental and physical traits of a thousand gifted children. In L. M. Terman (Ed.), Genetic studies of genius (2nd ed., Vol. 1). Stanford, CA: Stanford University Press.

Thorndike, E. L. (1950). Traits of personality and their intercorrelations as shown in biographies. Journal of Educational Psychology, 41(4), 193-216. doi:10.1037/ h0055716

Trost, G. (2000). Prediction of excellence in school, higher education, and work. In K. A. Heller, F. J. Mönks, R. J. Sternberg, \& R. F. Subotnik (Eds.), International handbook of giftedness and talent (2nd ed., pp. 317-325). Oxford, England: Elsevier Science.

Wai, J., Lubinski, D., \& Benbow, C. P. (2005). Creativity and occupational accomplishments among intellectually precocious youths: An age 13 to age 33 longitudinal study. Journal of Educational Psychology, 97(3), 484492. doi:10.1037/0022-0663.97.3.484

Winner, E. (2000). The origins and ends of giftedness. American Psychologist, 55(1), 159-169. doi:10.1037/0003-066X.55.1.159

Zimmerman, B. J. (2002). Becoming a self-regulated learner: An overview. Theory Into Practice, 41(2), 64-72.

Seille Cristine Garcia-Santos é Doutora em Psicologia pelo Programa de Pós-graduação em Psicologia da Faculdade de Psicologia da Pontifícia Universidade Católica do Rio Grande do Sul.

Leandro da Silva Almeida é Professor Catedrático do Instituto de Educação da Universidade do Minho.

Blanca Susana Guevara Werlang é Professora Titular da Faculdade de Psicologia da Pontifícia Universidade Católica do Rio Grande do Sul.

Recebido: 29/01/2010

$1^{a}$ revisão: $15 / 06 / 2010$

Aceite final: 21/01/2011

Como citar este artigo:

Garcia-Santos, S. C., Almeida, L. S., \& Werlang, B. S. G. (2012). Human excellence: The contribution of personality. Paidéia (Ribeirão Preto), 22(52), 271-279. doi:10.1590/S0103-863X2012000200011 